Memishi Shpresa, Ameti Vullnet, Arifi Fitim. Standing Height and Its Estimation Utilizing Length of Hand Measurements of Both Gender Adolescents from North Region of Kosovo; District of Mitrovica. Journal of Education, Health and Sport. 2019;9(12):11-18. eISSN 2391-8306. DOI http://dx.doi.org/10.12775/JEHS.2019.09.12.001

https://apcz.umk.pl/czasopisma/index.php/JEHS/article/view/JEHS.2019.09.12.001

https://zenodo.org/record/3564748

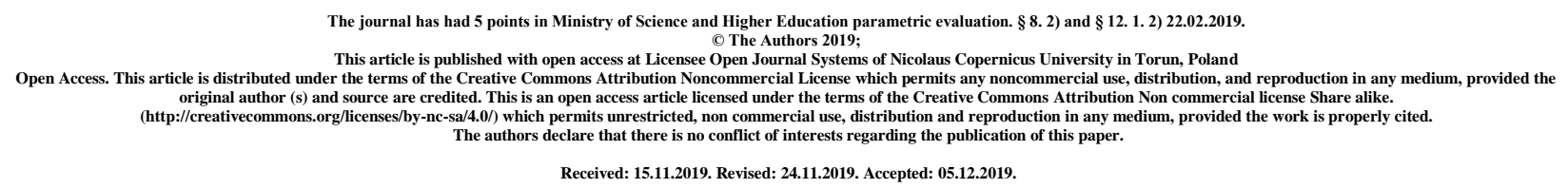

\title{
Standing Height and Its Estimation Utilizing Length of Hand Measurements of Both Gender Adolescents from North Region of Kosovo; District of Mitrovica
}

\author{
Shpresa Memishi ${ }^{1}$, Vullnet Ameti ${ }^{1}$, Fitim Arifi ${ }^{1,2}$ \\ ${ }^{1}$ University of Tetova, Faculty for Sport and Physical Education, Tetova, North Macedonia \\ ${ }^{2}$ Universi College, Department of Physical Culture, Sport and Recreation, Prishtina, Kosovo
}

\begin{abstract}
Purpose of this study was to examine the standing height of adolescents from district of Mitrovica north region of Kosovo, as well relationship between the length of the hand and standing height from both gender adolescents. A total measured subject participated in this research was 177 students from high school graduates (87 male and 90 female) females average of age is $18.28 \pm 0.45$ years old (range 18-20 years) and for male $18.25 \pm 0.46$ years old (range 1820 years). The anthropometric measurements were done by trained people and were taken according to the ISAK manual. The results for body height and length of the hand were analyzed by means of the arithmetic mean (SD) and a simple correlation coefficient, while T-test analysis was used for differences between the two genders and linear regressive analysis assessed body height based on length of hand measurements. The results obtained in this paper have shown that body height can be estimated from the length of the hand, which reliably predicts body height for both genders.
\end{abstract}

Key words: Measurements, Body Height, Hand Length, Mitrovica, Genders

\section{Introduction}

Kosovo is located in the central part of the Western Balkans. Roads across Kosovo connect the Adriatic and the Aegean within the interior of the Balkan Peninsula. Its borders are shared with Albania $(112 \mathrm{~km})$, Macedonia $(160 \mathrm{~km})$, Montenegro $(76 \mathrm{~km})$ and Serbia $(366 \mathrm{~km})$. Kosovo's borders with neighboring countries mainly cross mountains and are of a natural character: to the west of Kosovo, the border is with Bjeshket e Nemuna; to the north, it is with Sharr Mountain and Pashtrik; and, to the north and north-east, it is with Kopaonik. The eastern perimeter of the 
Kosovo Basin is lower and thus waters flow into the North Morava Valley and Toplica. The north-western part of Dukagjini, between Pashtrik and Koritnik, is also lower and the White Drin flows there. Mountains make up about $63 \%$ of the territory of Kosovo and are divided into several groups: suburban and central, and high, middle and low mountains. The Dinaric Mountains belong to the western part of Kosovo. The Inner Dinaric Mountains include Mount Mokna and the Mali i Thatë and the Bjeshkët e Nemuna Mountains. Kosovo's climate is conditioned by geographical location. Extending through the medium latitude, Kosovo's climate is conditioned by the amount of sunshine, and its proximity to the Adriatic Sea, the Vardar Valley, and the opening to the north, where the altitude averages $400 \mathrm{~m}$ (16). Based on the available data, Kosovo lies within several different geographical regions and its population belongs to the Central Dinaric Zone; thus, it is highly important to conduct a professional study that would provide a morphometric estimate of the entire population. With different geographical and administrative regions (Pristina, Mitrovica, Peja, Gjakova, Mitrovica, Ferizaj \& Gjilan), Kosovo has a territory of 10,887 km2 and 1,907,592 inhabitants (July 2018 estimate), whose average age is 29.6 years, while $50.34 \%$ are male and $49.66 \%$ female. This study analyzes the relationship between standing height and length of the hand measurements in adolescents in the north region of Kosovo. Within this region is administrative districts of Mitrovica and four municipalities ((Leposavić, Mitrovica, North Mitrovica, Skenderaj, Vushtrri, Zubin Potok and Zvečan). This region (Figure 1) covers the area of 2,077 square kilometers and has population of 272,247 inhabitants, while average density per square kilometer is 110 inhabitants (Komunat e Kosovës,2013).

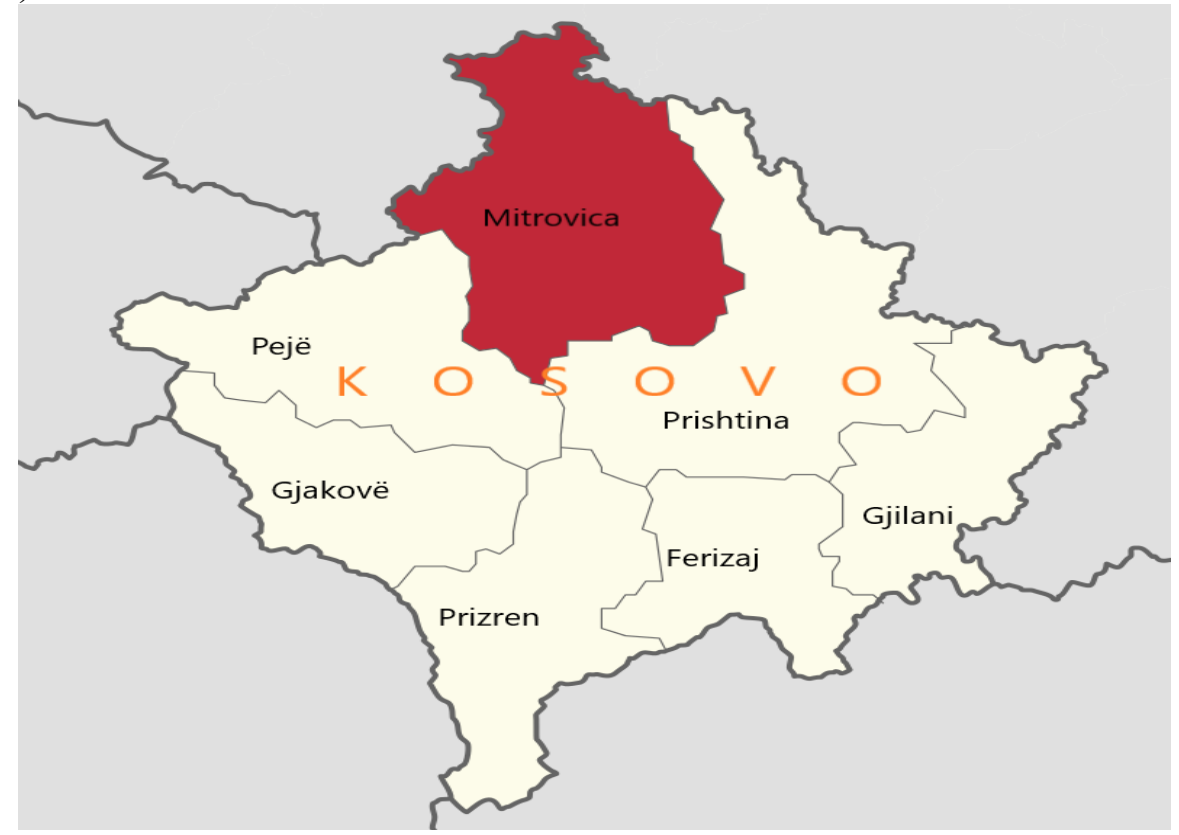

Geographical Location District of the Mitrovica (Figure 1)

The human body and their inter-relationships have awakened the curiosity of many authors around the world undertaking research in this regard by comparing relations between different races, as well as within a population but from different geographical regions (Bjelica et al., 2012; Arifi et al., 2017a; Arifi et al., 2017b; Arifi et al., 2017c; Popovic et al., 2016). The dimensions of the body that has been most frequently addressed by research in relation to other anthropometric parameters is body height, which is widely recognized as one of the most significant anthropometric measures whose values can be used for various purposes, such as 
assessing children's growth and development, nutrition, overweight, talent identification and energy consumption, thereby underlining the importance of accurately recognizing these values (Datta Banik, 2011; Rexhepi, Brestovci \& Isufi, 2018). However, body height is not always possible to measure in the traditional way, for example, in cases where an individual has some form of paralysis, fractures, amputations, scoliosis, kyphosis, osteoporosis, hormonal imbalances and various kinds of pain (Quanjer et al., 2014;). In such cases, we need to estimate relative body height using other anthropometric parameters as reliable predictors, such as arm span, which has been established by many authors to be one of the best predictors of body height compared to, among others, sitting height, hand length, vertebral column length, tibia length, foot length and sternum length. Research indicates that the relationships between body height and other anthropometric parameters are different and vary from race to race, ethnicity to ethnicity, and region to region (Bjelica et al., 2012; Agnihotri et al., 2007; De Lucia et al., 2002; Mohanty et al., 2001;). According to a study conducted by Quanjer et al. (2014), body height relative to other anthropometric parameters varies non-linearly, based on the age between males and females. It is especially interesting to note that a number of scientific studies has confirmed that people who are tall suffer more from heart disease, as well as some types of cancer, earlier damage to the joints and spine, etc., but, in other cases, tall people also enjoy more privileges in society, usually have higher social positions, are more successful at school and in a considerable range if sports and sports-related (Popović, Arifi \& Bjelica, 2017a; Arifi, 2018).

A big number of studies has been conducted worldwide on body height to arm span ratios involving anthropometric parameters, using similar samples to the adolescent population of Kosovo in general (Arifi et al., 2017a; Arifi, 2017b; Arifi et al., 2017c), as well as on body height to foot length ratios (Arifi, Gardasevic \& Masanovic, 2018), body height to sitting height ratios (Popovic, 2018; Gardasevic, Masanovic \& Arifi, 2018) and body height to tibia length ratios (Masanovic, Gardasevic \& Arifi, 2019). Based on the above research, it is very important for the population of Kosovo to have accurate information as well as body height to length of hand ratios, which are of great importance to medicine, sports, anthropology and other fields. Hence, the first aim of this research is to examine the average body height of adolescents for both genders region of Mitrovica, as the authors believe that adolescents of Mitrovica population can reach full potential for the Dinaric race, while the second aim is to examine body height for both genders in Kosovo and its relationship to hand length.

\section{Method}

The included a sample of 177 high school graduates from north region of Kosovo - District of Mitrovica 87 are male and 90 females average of age is $18.28 \pm 0.45$ years old (range 18-20 years) and for male 18.25 \pm 0.46 years old (range 18-20 years). We chose to obtain measurements from graduates because, being 18 years old, it was expected that, at the time of measurement, body growth and development had been completed for both genders and maximum body height had been reached. It is also worth noting that the sampling criterion was random on the day the measurements were made, but all students were included, regardless of whether or not they had any physical disabilities and/or and were permanent residents in region of Mitrovica. The measurements were made by experts from the Institute of Sport Anthropology and the National Centre for Sport Medicine, both in Pristina. Measurements of body height and hand length were performed by reference to the protocol of the International Association for the Advancement of Kinanthropometry (Marfell-Jones, Olds, Steele \& Carter, 2006). Whereas students' age data were obtained at the time of the measurements and each person's age was calculated from his/her 
date of birth and the date the measurements were made. The results for body height and hand length were calculated using the SPSS version 25.0 mathematical package for each individual. The arithmetic mean (SD) was calculated for both genders, while T-test analysis was performed with regard to the two anthropometric variables, differences between body height and hand length for each sex group and between genders. The ratios between body height and length of hand were determined via Pearson's correlation coefficient with a 95 per cent confidence limit. Meanwhile, to determine the extent to which the length of the hand can predict body height, linear regressive analysis was employed. The significance of the statistical coefficient was set at the level of $\mathrm{p}<0.05$.

\section{Results}

A summary of the results for the anthropometric measurements of both genders are presented in Table 1. The arithmetic mean of body height in males is $180.28 \pm 5.71$ centimetres and the length of the hand is $19.12 \pm 0.84$ centimetres, while, in females, the arithmetic mean is $165.36 \pm 4.56$ centimetres for body height and $17.52 \pm 0.78$ centimetres for hand length. Differences between males and females in the case of anthropometric measurements of body height and length of hand were statistically significant at (males: $t=6.949, \mathrm{p}<0.000$; females: $\mathrm{t}=6.450, \mathrm{p}<0.000$ ).

Table 1: Anthropometric measurements for both genders

\begin{tabular}{ccc}
\hline \multirow{2}{*}{ Subjects } & $\begin{array}{c}\text { Standing Height Range } \\
(\text { Mean } \pm \text { SD) }\end{array}$ & $\begin{array}{c}\text { Length of Hand Range } \\
(\text { Mean } \pm \text { SD) }\end{array}$ \\
\hline \multirow{2}{*}{ Male } & $167.9-197.3$ & $16.8-8-21.8$ \\
& $(180.28 \pm 5.71)$ & $(19.12 \pm 0.84)$ \\
\multirow{2}{*}{ Female } & $158.70-182.0$ & $15.7-20.0$ \\
& $(165.36 \pm 4.56)$ & $(17.52 \pm 0.78)$ \\
\hline
\end{tabular}

The simple correlation coefficient and analysis of the $95 \%$ confidence interval between anthropometric measurements are presented in Table 2 . The correlations between body height and the length of the hand are significant $(\mathrm{p}<0.000)$ and the correlations between the two anthropometric variables are high for both genders (males: 0.602; females: 0.567).

Table 2. Correlation between body height and hand length of the study subjects

\begin{tabular}{cccc} 
Subjects & $\begin{array}{c}\text { Correlation } \\
\text { Coefficient }\end{array}$ & $\begin{array}{c}95 \% \text { confidence } \\
\text { interval }\end{array}$ & $\begin{array}{c}\text { Significance } \\
\text { p-value }\end{array}$ \\
\hline Male & 0.602 & $0.430-0.774$ & $<0.000$ \\
Female & 0.567 & $0.392-0.741$ & $<0.000$ \\
\hline
\end{tabular}

The results of the linear regressive analysis are presented in Table 3 . The results of the regression coefficient are high (males: 0.602; females: 0.567), while the results of body height prediction for adolescents from the length of the hand for both genders are as follows: males: $\quad t=$ 6.949, $\mathrm{p}<0.000$; females: $\mathrm{t}=6.450, \mathrm{p}<0.000$. These results are confirmed by the coefficient of determination, denoted as R-squared (\%), for males at 36.2 and for females at 32.1. 
Table 3. Results of linear regression analysis where hand length predicts body height

\begin{tabular}{cccccc}
\hline Subjects & $\begin{array}{c}\text { Regression } \\
\text { Coefficient }\end{array}$ & $\begin{array}{c}\text { Standard } \\
\text { Error }(\mathrm{SE})\end{array}$ & $\begin{array}{c}\text { R-square } \\
(\%)\end{array}$ & t-value & p-value \\
\hline Male & 0.602 & 4.591 & 36.2 & 6.949 & 0.000 \\
Female & 0.567 & 3.781 & 32.1 & 6.450 & 0.000 \\
\hline
\end{tabular}

The associations between body height measurements and length of the hand among the above models is sketched as a scatter diagrams (Figure 2).

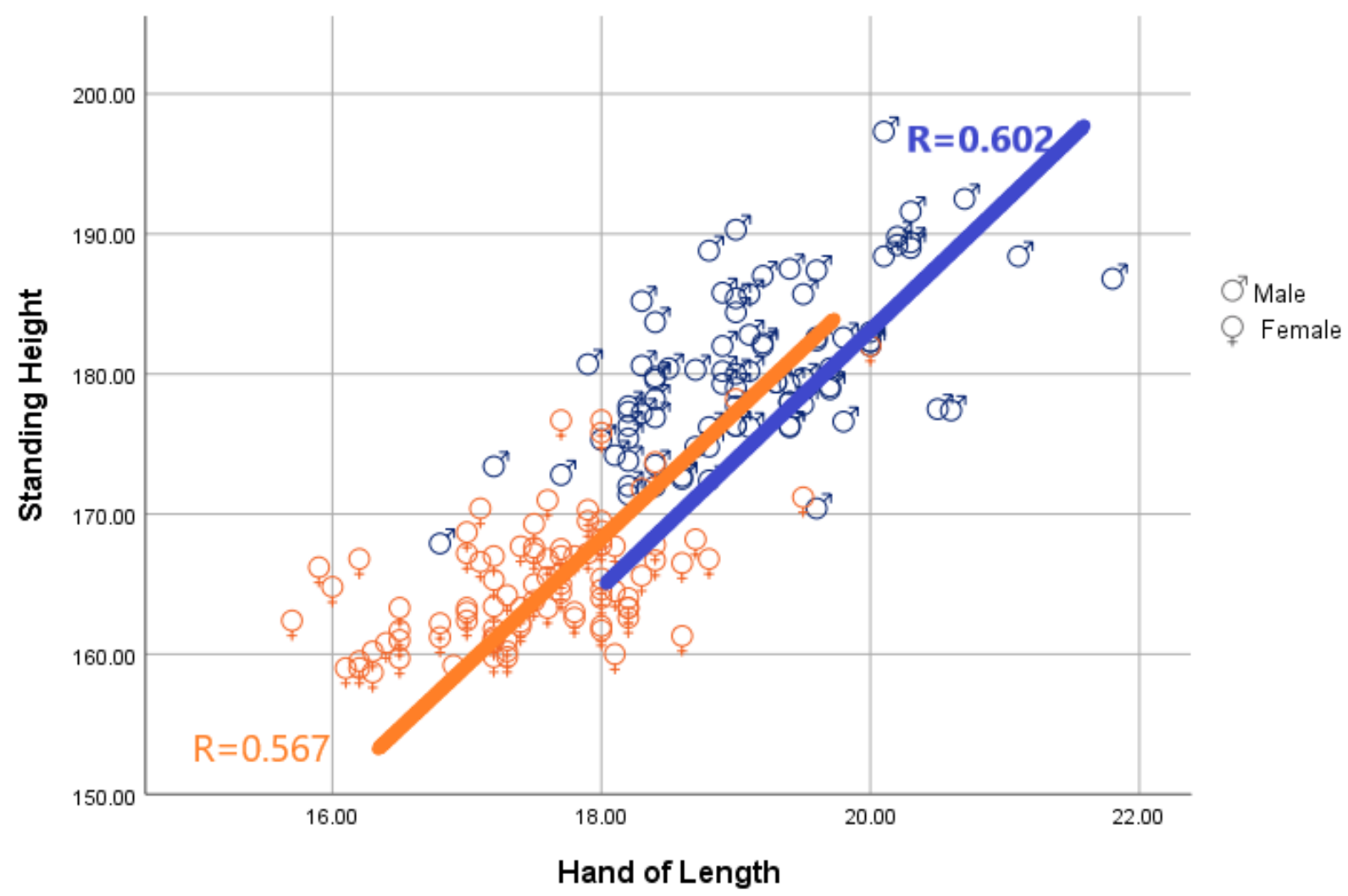

Figure 2. Scatter Diagram and Relationship between Length of Hand Measurements and Body Height among Both Genders

\section{Discussion}

Through this study, it can be established that adolescents from north region of Kosovo, district of Mitrovica are ranked very high in the world, with an average body height of $180.28 \pm 5.71$ centimetres, and are higher to the data that was reached in the measurement of Kosovo males population with an average standing height of $179.52 \pm 5.96$ centimetres (Arifi et al., 2017a). Compared to countries in the region such as Macedonia, adolescents from district of Mitrovica are taller than those with an average height of 178.10 centimetres (Popovic et al., 2016), However, adolescents from Mitrovica are not taller than Montenegrins, whose height is 183.36 centimetres on average (Popovic, 2017), the population of the Dinaric Alps at 28 per cent (Pineau et al., 2005).

In addition, female adolescents from region of Mitrovica are among the world's tallest populations with an average height of $165.36 \pm 4.56$ centimetres are same than to the data that 
was reached in the measurement of Kosovo females population with an average standing height of $165.72 \pm 4.80$ centimetres (Arifi et al., 2017). Compared to countries in the region, such as Macedonia, female from Mitrovica are taller than those in Macedonia with an average height of 164.58 centimetres (Popovic et al., 2016). But adolescents from Mitrovica are not taller than females from the Netherlands, having a height of 168.8 centimetres (Statistics Netherland, 2015), or with females from Montenegro averaging 168.3 centimetres (Bjelica et al., 2012).

This research is still not complete, because the other main aim was to estimate body height from the length of the hand and the links between them in the case of measurements for both genders among Mitrovica adolescents. Besides arm span, sitting height, foot length and tibia length (Arifi et al., 2017; Popovic, 2019; Gardasevic, 2019) have proven to be good predictors of body height in our study. Hand length, using deterministic equations has been shown to be reliable predictors, especially with regard to the body height of Mitrovica adolescents of both genders. Research by different authors has revealed that the dimensions of hand length vary from race to race and therefore the formulas that can be applied to one ethnic group are not necessarily applicable to others, on account of genetic, environmental and socioeconomic factors (Lukpata et al., 2015;). That said, some studies have demonstrated that differences can also be individual (Dubois et al., 2012;).

This study confirms the existence of differences in body height and hand length which are statistically significant between males and females, where the mean length of hand was $19.12 \pm$ 0.84 centimetres for males and $17.52 \pm 0.78$ centimetres for females, and the difference was significant at the $\mathrm{p}<0.000$ level; this has also been validated by other authors (Agnihotri et al., 2007; Rastogi et al., 2008;). Relationships between body parameters have been the focus of years of research for many anthropologists, which is why we have also tried to validate the correlation between body length and the length of the hand. The present study reports high values for the correlation coefficient between body length and hand length measurements for both genders, while the correlation between body length and hand length for males is $(r=0.602)$ and, for females, it is $(r=0.567)$; these results are comparable to those found in other studies from Europe and the rest of the world. Recent studies have presented results similar to those in the study from Wakode et al. (2015) who found a high correlation between body height and male hand length with a value of $(r=0.699)$ and female hand length with a value of $(r=0.693)$. Similar correlation values between body height and hand length in the Egyptian population have been found by Muhammad (2013), who found a correlation between these two parameters of $(\mathrm{r}=$ $0.525)$ for males and $(r=0.697)$ for females. Comparable findings for stature and hand length have been reported by Moorthy and Zulkfly (2014), with values of $(r=0.604)$ for males and $(r=$ 0.630) for females. Uhrova et al. (2015), in her study on Slovak youth, observed a correlation between body height and hand length of $(\mathrm{r}=0.630)$ for males and $(\mathrm{r}=0.580)$ for females, and Ozalsan et al. (2012) found a correlation between body height and hand length of $(r=0.578)$ for males and $(r=0.309)$ for females, while Patel et al. (2012) found higher values between body height and the length of male hands $(r=0.806)$.

On account of the models applied in this paper, it is evident that body height showed a high correlation with hand length and confirmed that body height can be estimated from the length of the hand among district of Mitrovica adolescents. The limitation of this study is that the male and female adolescents from Mitrovica included in this study were born in 1998, which was a period of war in Kosovo, when half the population were displaced from their homes. Their lives have been lived under difficult socioeconomic conditions. As the authors of this paper, we conclude that the average stature of male and female from district of Mitrovica has not yet reached its full 
maximum genetic potential and that it is expected that future generations will achieve greater body height and be among the tallest populations the world. It is therefore necessary to consider different models for population research in Kosovo, based on each region and both genders.

\section{CONFLICT OF INTEREST}

The author declare no conflict of interest.

\section{References}

Agnihotri, A. K., Agnihotri, S., Jeebun, N. \& Googoolye, K. Prediction of stature using hand dimensions. Journal Forensic Legal Medicine, 15(8):479-82, 2008.

Arifi, F. Gardašević, J. \& Masanović, B. Relationship between foot length measurements and body height: A prospective regional study among adolescents in Central region of Kosovo. Sport Mont Journal 16(3):75-79,2018.

Arifi, F., Bjelica, D., Sermaxhaj, S., Gardasevic, J., Kezunovic, M., \& Popović, S. Stature and its Estimation Utilizing Arm Span Measurements in Kosovan Adults: National Survey.

International Journal of Morphology, 35(3):1161-1167, $2017 \mathrm{a}$.

Arifi, F., Sermaxhaj, S., Zejnullahu-Raçi, P., Alaj, I., \& Metaj, Z. Stature and its estimation utilizing arm span measurements of both gender adolescents from northern region in Kosovo. Acta Kinesiologica, 11(9): 49-52, 2017b.

Arifi, F. Stature and its estimation utilizing arm span measurements of both gender adolescents from northeast region in Kosovo. Sports Science, 10(1):92-95, 2017c.

Bjelica, D., Popović, S., Kezunovic, M., Petkovič, J., Jurak, G., \& Grasgruber, P. Body height and its estimation utilizing arm span measurements in Montenegro adults, Anthropological Notebooks, 18(2): 69-83, 2012.

Datta Banik, S. Arm span as a proxy measure for height and estimation of nutritional status: A study among Dhimals of Darjeeling in West Bengal India. Annals of Human Biology, 38(6):72835, 2011.

De Lucia, E., Lemma, F., Tesfaye, F., Demisse, T. \& Ismail. S. The use of armspan measurement to assess the nutritional status of adults in four Ethiopian ethnic groups. European Journal of Clinical Nutrition, 56(2):91-5, 2002.

Dubois, L., Ohm, Kyrik., Girard, M., Tatone-Tokuda, F. \& Perusse, D. Genetic and environmental contributions to weight, height and BMI from birth to 19yrs of age. Aninternational study over 12,000 twin pairs. PLOS ONE 7(2): 30153, 2012.

Gardašević, J. Masanović, B. \& Arifi, F. Relationship between tibia length measurements and standing height: A prospective regional study among adolescents in northern region of Kosovo. Sport Mont Journal, 16(3):51-55, 2018.

Çavolli, R. Gjeografia Regjionale e Kosovës. Enti i teksteve dhe i mjeteve mësimore i Kosovës, Prishtinë, 1997.

Lukpata, P., Ojim, U. O., Esemonu, U. G., Okori, S. O., Egwu, A. O. \& Ude, R. Stature estimation from hand dimensions in Bekwara ethnic group of cross River State, Nigeria The International Journal of Science and Technoledge, 3(9):267-270, 2015.

Marfell-Jones, M.; Olds, T.; Stew, A.D. \& Carter, J.E.L. International standards for anthropometric assessment. Potchesfstroom: International Society for the Advancement of Kinanthropometry, 2006. 
Masanović, B., Gardašević, J \& Arifi, F. Relationship between foot length measurements and body height: A prospective regional study among adolescents in northern region of Kosovo. Anthropologie LVII(2): 227-233,2017.

Mohamed, M. H. Measurement of Foot and Hand Dimensions andtheir Correlation with Height in Adult Upper Egyptians. Al_Azhar Assiut Medical Journal, 11(4): 300-318, 2013.

Moorthy, T. N. \& Zulkifly, N. R. B. Regression Analysis for Stature Determination from Hand Anthropometry of Malaysian Malays for Forensic Investigation. Sri Lanka Journal of Forensic Medicine, Science \& Law, 5(2): 8-15, 2014.

Ozaslan, A. Karadayi, B. Kolusayin, M.O. Kaya1, A. \& Afsin, H. Predictive role of hand and foot dimensions in stature estimation. Rom J Leg Med. (20): 41-46, 2012.

Patel, P. N., Tanna J. A. \& Kalele, S. D. Correlation between hand length and various anthropometric parameters. International Journal Of Medicine Toxiology and Forensic Medicine, 2 (2):61-63, 2012.

Pineau, JC., Delamarche, P., \& Bozinovic, S. Average height of adolescents in the Dinaric Alps. Comptes Redus Biologies, 328(9):841-6, 2005.

Popović, S., Bjelica, D., Georgiev, G., Krivokapic, D. \& Milasinovic, R. Body Height and its Estimation Utilizing Arm Span Measurements in Macedonian Adults. Anthropologist, 24(3): 737-45, 2016.

Popović, S., Arifi, F., \& Bjelica, D. Standing Height and its Estimation Utilizing Foot Length Measurements in Kosovan Adults: National Survey. International Journal of Applied Exercise Physiology, 6(2): 1-7, 2017.

Quanjer, P.H.; Capderou, A.; Mazocioglu, M.M.; Aggarwal, A.; Popovic, S.; Datta Banik, S.; Tayie, F.A.K.; Golshan, M.; Ip, M.S.M. \& Zelter, M. All-age relationship between arm span and height in different ethnic groups. European Respiratory Journal, 44(4): 905-12, 2014.

Rexhepi, A., Brestovci, B., \& Isufi, I. Normative Values of Some Morphometric Variables for Kosovo Albanian Population Aged 06 - > 70 Years Old. International Journal of Morphology 36(2):592-597, 2018.

Statistics Netherland. Lifestyle, preventive screening; sex, age, 2015. Retrieved on March 15, 2016,fromhttp://statline.cbs.nl/StatWeb/publication/? dm=slen\&pa=8117eng\&d1=13-24\&d2=1$2 \& \mathrm{~d} 3=\mathrm{a} \& \mathrm{~d} 4=0 \& \mathrm{~d} 5=1 \& \mathrm{la}=\mathrm{en} \& \mathrm{vw}=\mathrm{t} /$.

Uhrova, P., Benus, R., Masnicova, S. Obertova, Z., Kramarova, D., Kyselicova, K., Dornhoferova, M., Bodorikova, S. \& Nescakova, E. Estimation of stature using hand and foot dimensions in Slovak adults. Legal medicine, 17(2):92-7, 2015.

Wakode, N. S.,Wakode, S. L., Ksheersagar, D. D.,Tajane, V. D. \& Jachak, A.N. Prediction of Stature based on Measurement of Hand Lengthin Maharashtra Region. Indian Journal of Clinical Anatomy and Physiology,2(3): 131-135, 2015.

\section{*Corresponding Author:}

Fitim Arifi, Professor Assistant

Physical Culture, Sport and Recreation, Universi College,

Prishtina, Kosovo

Tel: 00383 (44) 250950

E-mail: fitim.arifi@kolegjiuniversi-edu.net 